\title{
Diatomáceas epilíticas da subordem Sellaphorineae do rio do Monjolinho, São Carlos, SP, Brasil
}

\author{
Maria das Graças Machado de Souza ${ }^{1,2}$ e Pedro Américo Cabral Senna ${ }^{\dagger}$
}

Recebido em 19/07/2007. Aceito em 17/09/2008

RESUMO - (Diatomáceas epilíticas da subordem Sellaphorineae do rio do Monjolinho, São Carlos, SP, Brasil). O presente trabalho é uma contribuição ao conhecimento da biodiversidade de diatomáceas epilíticas pertencentes à subordem Sellaphorineae do rio do Monjolinho, localizado no Município de São Carlos, São Paulo. O estudo taxonômico baseou-se na análise de 33 amostras coletadas no período de maio a outubro de 1998, em seis estações de coleta previamente estabelecidas. Foram identificados 31 táxons específicos e infra-específicos dos quais 29 são citações pioneiras para o estado de São Paulo.

Palavras-chave: algas epilíticas, diatomáceas, lótico, Sellaphorineae, taxonomia

ABSTRACT - (Epilithic diatoms of the suborder Sellaphorineae from Monjolinho River, São Carlos, São Paulo, Brazil). This is a survey of epilithic diatom biodiversity of Sellaphorineae from Monjolinho river, in São Carlos district, São Paulo state. The taxonomic study was carried out based on 33 samples collected between May and October 1998 at six selected stations. Thirty one specific and infraspecific taxa were identified; twenty nine of these were recorded for the first time in São Paulo state.

Key words: diatoms, epilithic algae, lotic, Sellaphorineae, taxonomy

\section{Introdução}

O conhecimento da ficoflórula do Estado de São Paulo é bem significativo, porém quando se trata das diatomáceas existem poucos estudos para o estado. Vale ressaltar que boa parte das informações reunidas se encontram em dissertações de mestrado e teses de doutorado, que em muitos casos não foram publicadas, tornando-se uma literatura de difícil acesso para grande parte dos pesquisadores.

O estudo das Sellaphorineae no Estado de São Paulo está resumido em 15 trabalhos, dos quais duas são dissertações de mestrado e seis teses de doutorado. Dos demais trabalhos, seis são de natureza ecológica. Três apenas fazem referência a algum representante da subordem Sellaphorineae, não sendo possível a sua re-identificação (Bicudo \& Bicudo 1967; Tundisi \& Hino 1981; Xavier et al. 1985). Os trabalhos de Sant'Anna et al. (1989), Magrin \& Senna (1997) e Metzeltin \& LangeBertalot (1998) apesar de serem, também, ecológicos, eles possuem dados que permitem que os táxons inventariados sejam estudados novamente. Apenas um único, o de Bicudo et al. (1993) é de cunho taxonômico, nele foram registrados 51 táxons infra-genéricos de Bacillariophyceae para um trecho do rio Paranapanema, que foi represado para construção da usina hidrelétrica de Rosana. Neste trabalho foi descrita e ilustrada apenas uma espécie da subordem Sellaphorineae, Navicula pupula Kützing var. pupula (atualmente Sellaphora pupula (Kützing) Mereschkowsky var. pupula).

O trabalho teve como objetivo realizar um estudo taxonômico das diatomáceas da subordem Sellaphorineae no rio do Monjolinho, São Paulo. Além de, contribuir para a taxonomia e distribuição geográfica dos táxons pertencentes a esta subordem em ambientes lótico no Brasil.

\section{Material e métodos}

A bacia hidrográfica do rio do Monjolinho possui, aproximadamente, $43,3 \mathrm{~km}$ de extensão e faz parte da bacia do rio JacaréGuaçú, um dos afluentes mais importantes do rio Tietê. Está localizada entre as coordenadas geográficas $47^{\circ} 50^{\prime}-48^{\circ} 05^{\prime} \mathrm{W}, 22^{\circ} 06^{\prime}-25^{\circ} 57^{\prime} \mathrm{S}$, no município de São Carlos.

A análise da diatomoflórula foi realizada com base em 33 amostras coletadas, mensalmente, no período de maio a outubro/1998, em seis estações de amostragem ao longo do rio do Monjolinho, que foram: estação 1, situada cerca de $2 \mathrm{~km}$ da nascente, na fazenda Santa Terezinha, bairro Babilônia, trecho rural; estação 2, distante aproximadamente $9,1 \mathrm{~km}$ da nascente, sob a rodovia Washington Luiz após a canalização do rio, inicio da área urbana; estação 3, localizada a mais ou menos $17,1 \mathrm{~km}$ da nascente, trecho após o lançamento de praticamente todo o esgoto da cidade de São Carlos; estação 4 , situada à cerca de $21,1 \mathrm{~km}$ da nascente, após deságüe dos córregos Água Quente e Água Fria, trecho entre cultivo de cana-deaçúcar; estação 5, distante aproximadamente 29,8 km da nascente, próxima à usina da Serra, trecho rural e estação 6, localizada a mais ou menos $42,5 \mathrm{~km}$ da nascente, na fazenda São José, próxima da confluência com o rio Jacaré-Guaçú, trecho rural.

As amostras foram obtidas através de raspagem de no mínimo três rochas submersas segundo Lobo et al. (1996), que foram introduzidas no ambiente pelo menos um mês antes das coletas, e fixadas com solução de formaldeído $4 \%$.

Para o estudo qualitativo das diatomáceas o material foi oxidado, segundo a técnica de oxidação de Simonsen (1974) modificada por Moreira Filho \& Valente-Moreira (1981) e montado em lâminas permanentes com Naphrax ${ }^{\circledR}$. As amostras e as lâminas permanentes foram tombadas no Herbário da Universidade de Brasília (UB). Os táxons encontrados foram enquadrados segundo o sistema de classificação de Round et al. (1990).

\section{Resultados e discussão}

O estudo taxonômico das diatomáceas pertencentes à subordem Sellaphorineae do rio do Monjolinho foram identificados 31 táxons infragenéricos, dois pertencentes ao gênero Fallacia Stickle \& D.G. Mann, três ao Sellaphora Mereschkowsky, três ao Caloneis P. Cleve e 23 ao Pinnularia Ehrenberg, sendo 15 espécies e sete variedades não típicas da espécie.

\footnotetext{
1 Universidade de Brasília, Departamento de Botânica, Brasília, DF, Brasil

2 Autor para correspondência: gmachado@unb.br
} 
Dos táxons registrados 29 foram citados pela primeira vez para o Estado de São Paulo.

Sellaphorineae D.G. Mann

Sellaphoraceae Mereschokowsky

Fallacia Stickle \& D.G. Mann

Chave para os táxons de Fallacia

1. Valvas elípticas 1. F. insociabilis

1. Valvas lanceoladas 2. F. monoculata

1.Fallacia insociabilis (Krasske) D.G. Mann var. insociabilis, In Round, Crawford \& Mann, The Diatoms. Biol. \& morphol. of the genera, p. 668. 1990.

Navicula insociabilis Krasske, Hedwigia 72: 114. 1932.

Fig. 1

Valvas elípticas; extremidades arredondadas; área axial lanceolada, ligeiramente expandida no centro; área central indistinta; rafe filiforme, levemente encurvada, no interior de uma costela axial proeminente, constrita no centro; estrias curtas radiadas. Eixo apical: 9,61-29,1 $\mu \mathrm{m}$. Eixo transapical: 5,3-6,2 $\mu \mathrm{m}$. Estrias: 20-25/10 $\mu \mathrm{m}$.

Distribuição no Estado de São Paulo: citação pioneira para o Estado.

Material examinado: BRASIL. São Paulo: São Carlos, rio do Monjolinho, epilítica, bairro Babilônia, fazenda Santa Terezinha, V/1998, M.G.M. Souza s.n. (UB 01532); VI/1998 (UB 01573); São Carlos, rio do Monjolinho, epilítica, próximo à rodovia Washington Luiz, VI/1998, M.G.M. Souza s.n. (UB 01538); VII/1998 (UB 01543); X/1998 (UB 01560); São Carlos, rio do Monjolinho, epilítica, abaixo da Usina Hidrelétrica da CPFL, V/1998, M. G. M. Souza s.n. (UB 01534); VII/1998 (UB 01544); VIII/1998(UB 01550); IX/1998 (UB 01561); São Carlos, rio do Monjolinho, epilítica, a jusante dos córregos da Água Quente e Água Fria, VII/1998, M.G.M. Souza s.n. (UB 01545); X/1998 (UB 01562); São Carlos, rio do Monjolinho, epilítica, $50 \mathrm{~m}$ acima da ponte da estrada, próxima à Usina da Serra, VII/1998, M.G.M. Souza s.n. (UB 01546); X/1998 (UB 01563); São Carlos, rio do Monjolinho, epilítica, a montante da confluência com o rio Jacaré-Guaçú, V/1998, M.G.M. Souza s.n. (UB 01536); VIII/1998, (UB 01556); X/1998 (UB 01564).

2. Fallacia monoculata (Hustedt) D. G. Mann var. monoculata, In Round, Crawford \& Mann, The Diatoms. Biol. \& morphol. of the genera, p. 668. 1990.

Navicula monoculata Hustedt, Arch. Hydrobiol. 40: 921. 1945.

Fig. 2

Valvas lanceoladas; extremidades arredondadas; área axial arqueada; área central indistinta; rafe filiforme, levemente arqueada; estrias radiadas em toda a extensão da valva. Eixo apical: 11,3-15,1 $\mu \mathrm{m}$. Eixo transapical: 4,4-5,3 $\mu \mathrm{m}$. Estrias: $22-28 / 10 \mu \mathrm{m}$.

Distribuição no Estado de São Paulo: citação pioneira para o Estado.

Material examinado: BRASIL. São Paulo: São Carlos, rio do Monjolinho, epilítica, próximo à rodovia Washington Luiz, VI/1998, G. M. Souza s.n. (UB 01538); São Carlos, rio do Monjolinho, epilítica, a jusante dos córregos da Água Quente e Água Fria, V/1998, M.G.M. Souza s.n. (UB 01535); X/1998 (UB 01562); São Carlos, rio do Monjolinho, epilítica, $50 \mathrm{~m}$ acima da ponte da estrada, próxima à Usina da Serra, X/1998, M.G.M. Souza s.n. (UB 01563).

\section{Sellaphora Mereschkowsky}

\section{Chave para os táxons de Sellaphora}

1. Valvas lineares a linear-elípticas ....4. S. pseudopupula

1. Valvas lanceoladas a elíptico-lanceoladas

2. Extremidades rostradas a subcapitadas

2. Extremidades arredondadas .......... 5. S. seminulum

3. Sellaphora densistriata (Lange-Bertalot \& Metzeltin) Lange-Bertalot \& Metzeltin var. densistriata, Icon. Diatomol. 11:58. 2002.

Sellaphora pupula var. densistriata Lange-Bertalot \& Metzeltin, Icon. Diatomol. 2: 102, pl. 25, fig. 9. 1996.

Fig. 3

Valvas lanceoladas a elíptico-lanceoladas; extremidades rostradas a subcapitadas; área axial linear, estreita; área central transversalmente expandida mais ou menos retangular; rafe filiforme; extremidades proximais da rafe retas; nódulos terminais expandidos lateralmente; estrias irregularmente encurtadas no centro, curvo-radiadas ao longo de toda a valva. Eixo apical: 20,5-31,6 $\mu \mathrm{m}$. Eixo transapical: 7,4-8,1 $\mu \mathrm{m}$. Estrias: 20-24/10 $\mu \mathrm{m}$.

Distribuição no Estado de São Paulo: citação pioneira para o Estado.

Material examinado: BRASIL. São Paulo: São Carlos, rio do Monjolinho, epilítica, bairro Babilônia, fazenda Santa Terezinha, V/1998, M.G.M. Souza s.n. (UB 01532); VI/1998 (UB 01537); VII/1998 (UB 01542); VIII/1998 (UB 01548); IX/1998 (UB 01554); X/1998 (UB 01559); São Carlos, rio do Monjolinho, epilítica, próximo à rodovia Washington Luiz, V/1998, M.G.M. Souza s.n. (UB 01533); VI/1998 (UB 01538 ); VII/1998 (UB 01543); VIII/1998 (UB 01549); IX/1998 (UB 01555); X/1998 (UB 01560); São Carlos, rio do Monjolinho, epilítica, abaixo da Usina Hidrelétrica da CPFL, V/1998, M.G.M. Souza s.n. (UB 01534); VII/1998 (UB 01544); São Carlos, rio do Monjolinho, epilítica, a jusante dos córregos da Água Quente e Água Fria, V/1998, M.G.M. Souza s.n. (UB 01535); VI/1998 (UB 01539); VII/1998 (UB 01545); IX/1998 (UB 01556); X/1998 (UB 01562); São Carlos, rio do Monjolinho, epilítica, $50 \mathrm{~m}$ acima da ponte da estrada, próxima à Usina da Serra, VI/1998, M.G.M. Souza s.n. (UB 01540); VII/1998 (UB 01546); VIII/1998 (UB01552); IX/1998 (UB 01557); X/1998 (UB 01563); São Carlos, rio do Monjolinho, epilítica, a montante da confluência com o rio Jacaré-Guaçú, V/1998, M.G.M. Souza s.n. (UB 01536); VI/1998 (UB 01541); VII/1998 (UB 01547); VIII/1998 (UB 01553); IX/1998 (UB 01558); X/1998 (UB 01564). 
4. Sellaphora pseudopupula (Krasske) Lange-Bertalot var. pseudopupula, Icon. Diatomol. 3: 138, pl. 18, fig. 35-37. 1996.

Navicula pseudopupula Krasske, Botan. Arch. 3: 197, fig. 4. 1923.

Fig. 4

Valvas lineares a linear-elípticas; extremidades arredondadas; área axial linear, estreita; área central lateralmente expandida retangular; rafe filiforme; extremidades proximais da rafe levemente voltadas para o mesmo lado; estrias radiadas, irregularmente encurtadas no centro. Eixo apical: 22,9-31,0 $\mu \mathrm{m}$; Eixo transapical: 6,2 $\mu \mathrm{m}$. Estrias: $22-24 / 10 \mu \mathrm{m}$.

Distribuição no Estado de São Paulo: citação pioneira para o Estado.

Material examinado: BRASIL. São Paulo: São Carlos, rio do Monjolinho, epilítica, bairro Babilônia, fazenda Santa Terezinha, VII/1998, M.G.M. Souza s.n. (UB 01542); VIII/1998 (UB 01548); X/1998 (UB 01559).

5. Sellaphora seminulum (Grunow) D.G. Mann var. seminulum, Br. Phycol. J. 24: 2. 1989.

Navicula seminulum Grunow, Verh. Zool.-Bot. Ges. Wien 10: 552, pl. 4, fig. 3. 1860.

Fig. 5

Valvas lanceoladas a elíptico-lanceoladas; extremidades arredondadas; área axial linear, estreita; área central retangular; rafe filiforme; estrias radiadas, regularmente encurtadas no centro. Eixo apical: 7,4-14,3 $\mu \mathrm{m}$. Eixo transapical: 3,1-4,0 $\mu \mathrm{m}$. Estrias: 20-22/10 $\mu \mathrm{m}$.

Distribuição no Estado de São Paulo: citação pioneira para o Estado.

Material examinado: BRASIL. São Paulo: São Carlos, rio do Monjolinho, epilítica, bairro Babilônia, fazenda Santa Terezinha, V/1998, M.G.M. Souza s.n. (UB 01532); VI/1998 (UB 01537); VII/1998 (UB 01542); VIII/1998 (UB 01548); IX/1998 (UB 01554); X/1998 (UB 01559); São Carlos, rio do Monjolinho, epilítica, próximo à rodovia Washington Luiz, VII/1998, M.G.M. Souza s.n. (UB 01543); VIII/1998 (UB 01549); IX/1998 (UB 01555); X/1998 (UB 01560); São Carlos, rio do Monjolinho, epilítica, abaixo da Usina Hidrelétrica da CPFL, V/1998, M.G.M. Souza s.n.(UB 01534); VII/1998 (UB 01544); VIII/1998 (UB 01550); X/1998 (UB 01561); São Carlos, rio do Monjolinho, epilítica, a jusante dos córregos da Água Quente e Água Fria, V/1998, M.G.M. Souza s.n. (UB 01535); VI/1998 (UB 01539); VII/1998 (UB 01545); VIII/1998 (UB 01551); IX/1998 (UB 01556); X/1998 (UB 01562); São Carlos, rio do Monjolinho, epilítica, $50 \mathrm{~m}$ acima da ponte da estrada, próxima à Usina da Serra, VI/1998, M.G.M. Souza s.n. (UB 01540); VII/1998 (UB 01546); VIII/1998 (UB01552); IX/1998 (UB 01557); X/1998 (UB 01563); São Carlos, rio do Monjolinho, epilítica, a montante da confluência com o rio Jacaré-Guaçú,V/1998, M.G.M. Souza s.n. (UB 01536); VI/1998 (UB 01541); VII/1998 (UB 01547); VIII/1998 (UB 01553); IX/1998 (UB 01558); X/1998 (UB 01564).
Pinnulariaceae D.G. Mann

Caloneis P. Cleve

\section{Chave para os táxons de Caloneis}

1. Valvas intumescidas na região central .. 8. C. leptosoma

1. Valvas não intumescidas na região central

2. Estrias conspícuas .......................... 6. C. bacillum

2. Estrias inconspícuas .......................... 7. C. hyalina

6. Caloneis bacillum (Grunow) Cleve var. bacillum, Diatomiste 2 (17): 99. 1894.

Stauroneis bacillum Grunow, Verh. Zool. - Bot. Ges. Wien

13: 155, pl. 4, figs. 16a-b. 1863.

Fig. 6

Valvas lanceoladas a linear-lanceoladas; extremidades arredondadas a rostrado-arredondadas; área axial lanceolada; área central retangular atingindo as margens da valva, às vezes levemente assimétrica; rafe filiforme, reta; estrias paralelas. Eixo apical: 26,9-28,8 $\mu \mathrm{m}$. Eixo transapical: 5,9-6,8 $\mu \mathrm{m}$. Estrias: 22-23/10 $\mu \mathrm{m}$.

Distribuição no Estado de São Paulo: citação pioneira para o Estado.

Material examinado: BRASIL. São Paulo: São Carlos, rio do Monjolinho, epilítica, próximo à rodovia Washington Luiz, VI/1998, M.G.M. Souza s.n. (UB 01538); VII/1998 (UB 01543); VIII/1998 (UB 01549); X/1998 (UB 01560).

7. Caloneis hyalina Hustedt var. hyalina, Arch. Hydrobiol. Suppl. 15 (2): 281, pl. 15, figs. 8-10. 1937.

Fig. 7

Valvas lanceoladas a elíptico-lanceoladas; extremidades atenuado-arredondadas; área axial estreita, linear; área central retangular, assimétrica, alcançando as margens da valva; rafe filiforme, reta; estrias inconspícuas. Eixo apical: 12,4-27,9 $\mu \mathrm{m}$. Eixo transapical: 4,3-5,9 $\mu \mathrm{m}$.

Distribuição no Estado de São Paulo: citação pioneira para o Estado.

Material examinado: BRASIL. São Paulo: São Carlos, rio do Monjolinho, epilítica, bairro Babilônia, fazenda Santa Terezinha, V/1998, M.G.M. Souza s.n. (UB 01532); VI/1998 (UB 01537); VII/1998 (UB 01542); VIII/1998 (UB 01548); X/1998 (UB 01559); São Carlos, rio do Monjolinho, epilítica, abaixo da Usina Hidrelétrica da CPFL, V/1998, M.G.M. Souza s.n. (UB 01534); X/1998 (UB 01561); São Carlos, rio do Monjolinho, epilítica, a jusante dos córregos da Água Quente e Água Fria, X/1998, M.G.M. Souza s.n. (UB 01562); São Carlos, rio do Monjolinho, epilítica, a montante da confluência com o rio Jacaré-Guaçú, X/1998, M.G.M. Souza s.n. (UB 01564).

8. Caloneis leptosoma (Grunow) Krammer var. leptosoma, Bibl. Diatomol. 9: 18. 1985.

Navicula leptosoma Grunow, In Van Heurck, Syn. Diat. Belg. pl. 12, fig. 29. 1880.

Fig. 8 
Valvas lineares, intumescidas na região central; extremidades atenuado-arredondadas; área axial estreita, linear; área central retangular; rafe filiforme; extremidades proximais da rafe levemente voltadas para o mesmo lado; estrias fortemente radiadas no centro a paralelas nas extremidades. Eixo apical: 35,9 $\mu \mathrm{m}$. Eixo transapical: 5,7 $\mu \mathrm{m}$.
Estrias: $18 / 10 \mu \mathrm{m}$.

Distribuição no Estado de São Paulo: citação pioneira para o Estado.

Material examinado: BRASIL. São Paulo: São Carlos, rio do Monjolinho, epilítica, bairro Babilônia, fazenda Santa Terezinha, IX/1998, M.G.M. Souza s.n. (UB 01554).

Pinnularia Ehrenberg

Chave para os táxons de Pinnularia

1. Extremidades capitadas

2. Valvas trionduladas

3. Valvas nitidamente trionduladas

11. P. angusta var. angusta

3. Valvas ligeiramente trionduladas

4. Rafe complexa

25. P. similis var. similis

4. Rafe ligeiramente lateral

12. P. biceps var. biceps

2. Valvas não trionduladas

5. Área axial com granulações

9. P. acrosphaeria var. acrosphaeria

5. Área axial sem granulações

6. Margens valvares levemente côncavas

17. P. latarea var. latarea

6. Margens valvares retas ou convexas

7. Rafe filiforme

26. P. subanglica var. subanglica

7. Rafe lateral, filiforme no centro

8. Área axial linear-lanceolada

15. P. divergens var. media

8. Área axial linear

9. Valvas com mais de 10 estrias em $10 \mu \mathrm{m}$

28. P. subcapitata var. semicruciata

9. Valvas com 10 ou menos estrias em $10 \mu \mathrm{m}$ 27. P. subcapitata var. elongata

1. Extremidades não capitadas

10. Valvas com intumescência na região mediana

11. Área axial com granulações

11. Área axial sem granulações

9. P. acrosphaeria var. acrosphaeria 18. P. macilenta var. macilenta

10. Valvas sem intumescência na região mediana

12. Estrias cruzadas por bandas longitudinais

31. P. viridiformis var. minor

12. Estrias não cruzadas por bandas longitudinais

13. Estrias largas e espaçadas

14. Extremidades obtuso-arredondadas

13. $\boldsymbol{P}$. borealis var. borealis

14. Extremidades largo-arredondadas

14. $P$. borealis var. subislandica

13. Estrias de outra forma

15. Rafe lateral

16. Rafe estreitamente lateral

17. Margens levemente convexas ....

23. P. parvulissima var. parvulissima

17. Margens levemente côncavas na área central

20. P. microstauron var. brasiliensis

16. Rafe não estreitamente lateral

18. Valva linear-lanceolada

30. $P$. variarea var. variarea

18. Valva linear

19. Extremidades produzidas arredondadas

19. P. meridiana var. meridiana

19. Extremidades subcapitadas a largo-sub-rostradas

29. P. subgibba var. subgibba

15. Rafe filiforme

20. Valva linear

21. Extremidades subcapitadas

21. Extremidades rostradas

22. Área axial estreita

10. $P$. aff. anglica var. anglica

22. Área axial alargando-se da extremidade até a área central

20. Valva não linear

23. P. parvulissima var. parvulissima 
23. Área axial larga 22. P. cf. oominensis var. oominensis

23. Área axial estreita

24. Valva linear-elíptica 21. P. obscura var. obscura

24. Valva linear-lanceolada

25. Extremidades levemente rostradas 16. P. aff. doloma var. fascista

25. Extremidades obutso-arredondadas 24. P. schoenfelderi var. schoenfelderi

9. Pinnularia acrosphaeria W. Smith var. acrosphaeria, Syn. British Diat. 1: 58, pl. 19, fig. 183. 1853.

Fig. 9

Valvas lineares, levemente intumescidas na região central; extremidades largo-arredondadas a largo-capitadas; área axial ampla, linear, com granulações; área central assimétrica, expandida para um dos lados da valva; rafe lateral; extremidades proximais voltadas para lado, levemente dilatadas; extremidades distais em forma de foice; estrias paralelas ao longo da superfície valvar a levemente radiadas no centro, ligeiramente convergentes nas extremidades. Eixo apical: 49,8-53,3 $\mu \mathrm{m}$. Eixo transapical: 10,7-11,5 $\mu \mathrm{m}$. Relação eixo apical-eixo transapical: 5. Estrias: $13-14 / 10 \mu \mathrm{m}$.

Distribuição no Estado de São Paulo: citação pioneira para o Estado.

Material examinado: BRASIL. São Paulo: São Carlos, rio do Monjolinho, epilítica, a montante da confluência com o rio Jacaré-Guaçú, V/1998, M.G.M. Souza s.n. (UB 01536); VII/1998 (UB 01547); X/1998 (UB 01564).

10. Pinnularia aff. anglica Krammer var. anglica, Bibl. Diatomol. 26: 109, fig. 40: 21-23. 1992.

Fig. 10

Valvas lineares, margens retas; extremidades subcapitadas; área axial estreita, linear; área central abruptamente diferenciada da área axial, rômbica, ampla expandida lateralmente, atingindo as margens valvares; rafe filiforme; poros centrais nítidos, encurvados para o mesmo lado; estrias radiadas no centro, convergentes nas extremidades. Eixo apical: 31,4-44,4 $\mu \mathrm{m}$. Eixo transapical: 6,9-7,7 $\mu \mathrm{m}$. Estrias: 5-8/10 $\mu \mathrm{m}$.

O material registrado para o Monjolinho foi semelhante às ilustrações e descrição de Krammer (2000) para Pinnularia anglica Krammer. Porém, por ter apresentado eixo transapical e número de estrias em $10 \mu \mathrm{m}$ menores que o da bibliografia consultada optou-se por identificá-lo como, Pinnularia aff. anglica.

Distribuição no Estado de São Paulo: citação pioneira para o Estado.

Material examinado: BRASIL. São Paulo: São Carlos, rio do Monjolinho, epilítica, a montante da confluência com o rio Jacaré-Guaçú, V/1998, M.G.M. Souza s.n. (UB 01536); VII/1998 (UB 01547); X/1998 (UB 01564).

11. Pinnularia angusta (Cleve) Krammer var. angusta, Bibl. Diatomol. 26: 122, fig. 44: 16-20. 1992.

Pinnularia mesoplepta var. angusta Cleve, Kungl. Svensk.

Vetensk. Akad. Handl. 26/2: 76. 1895.

Fig. 11
Valvas lineares, margens nitidamente trionduladas; extremidades capitadas; área axial estreita, linear; área central rômbica, larga, atingindo as margens valvares; rafe filiforme; poros centrais nítidos, próximos, encurvados para o mesmo lado; estrias radiadas no centro, convergentes nas extremidades. Eixo apical: 38,4 $\mu \mathrm{m}$. Eixo transapical: 5,9 $\mu \mathrm{m}$. Relação: eixo apical-eixo transapical: 6,5. Estrias: $13 / 10 \mu \mathrm{m}$.

Os seguintes táxons propostos por Krammer (2000), $P$. grunowii Krammer e P. pluvianiformis Krammer são bastante semelhantes à $P$. angusta (Cleve) Krammer. A diferença entre eles está na relação eixo apical-eixo transapical. Nas espécies descritas por Krammer (2000) esta relação é de 3,7-5,4 e 4,5 respectivamente, na espécie $P$. angusta corresponde a 5,5-8,5. O único indivíduo encontrado no rio do Monjolinho foi identificado como $P$. angusta por apresentar a relação eixo apical-eixo transapical igual a 6,5.

Distribuição no Estado de São Paulo: citação pioneira para o Estado.

Material examinado: BRASIL. São Paulo: São Carlos, rio do Monjolinho, epilítica, bairro Babilônia, fazenda Santa Terezinha, VII/1998, M.G.M. Souza s.n. (UB 01542).

12. Pinnularia biceps Gregory var. biceps, Quart. Jour. Microsc. Sci. 4, p. 8, pl.1, fig.28. 1856.

Fig. 12

Valvas lineares, margens retas a levemente trionduladas; extremidades capitadas; área axial estreita, linear; área central rômbica, atingindo as margens valvares; rafe filiforme com extremidades proximais dilatadas e ligeiramente encurvadas para o mesmo lado; estrias radiadas no centro, convergentes nas extremidades. Eixo apical: 60,8-72,5 $\mu \mathrm{m}$. Eixo transapical: 10,5-11,5 $\mu \mathrm{m}$. Estrias: 10-11/10 $\mu \mathrm{m}$.

Distribuição no Estado de São Paulo: São Paulo (Bicudo \& Bicudo 1967) e Itirapina (Tundisi \& Hino 1981).

Material examinado: BRASIL. São Paulo: São Carlos, rio do Monjolinho, epilítica, bairro Babilônia, fazenda Santa Terezinha, V/1998, M.G.M. Souza s.n. (UB 01532); VI/1998 (UB 01537); VII/1998 (UB 01542); VIII/1998 (UB 01548); IX/1998 (UB 01554); X/1998 (UB 01559); São Carlos, rio do Monjolinho, epilítica, próximo à rodovia Washington Luiz, V/1998, M.G.M. Souza s.n. (UB 01533); VI/1998 (UB 01538 ); VII/1998 (UB 01543); VIII/1998 (UB 01549); IX/1998 (UB 01555); X/1998 (UB 01560); São Carlos, rio do Monjolinho, epilítica, abaixo da Usina Hidrelétrica da CPFL, V/1998, M.G.M. Souza s.n. (UB 01534); VII/1998 (UB 01544); VIII/1998 (UB 01550); X/1998 (UB 01564); São Carlos, rio do Monjolinho, epilítica, a jusante dos córregos da Água Quente e Água Fria, V/1998, M.G.M. Souza s.n. (UB 01535); 
VI/1998 (UB 01539); VII/1998 (UB 01545); VIII/1998 (UB 01551); IX/1998 (UB 01556); X/1998 (UB 01562); São Carlos, rio do Monjolinho, epilítica, $50 \mathrm{~m}$ acima da ponte da estrada, próxima à Usina da Serra, VI/1998, M.G.M. Souza s.n. (UB 01540); VII/1998 (UB 01546); VIII/1998 (UB01552); IX/1998 (UB 01557); X/1998 (UB 01563); São Carlos, rio do Monjolinho, epilítica, a montante da confluência com o rio Jacaré-Guaçú,V/1998, M.G.M. Souza s.n. (UB 01536); VI/1998 (UB 01541); VII/1998 (UB 01547); VIII/1998 (UB 01553); IX/1998 (UB 01558); X/1998 (UB 01564).

13. Pinnularia borealis Ehrenberg var. borealis, Abh. Königl. Akad. Wiss. Berl. 1841: 420, pl. 1/2, fig. 6, pl. 4/1, fig. 5. 1843. Fig. 13

Valvas lineares a linear-elípticas; extremidades obtusoarredondadas; área axial estreita; área central larga, arredondada; rafe levemente lateral; extremidades proximais rafe encurvados para o mesmo lado; poros centrais distintos, arredondados; estrias largas, distantes uma das outras, ligeiramente radiadas no centro a paralelas nas extremidades. Eixo apical: 35,6-44,6 $\mu \mathrm{m}$. Eixo transapical: 8,1-8,7 $\mu \mathrm{m}$. Estrias: $5 / 10 \mu \mathrm{m}$.

Distribuição no Estado de São Paulo: São Paulo (Sant'Anna, Azevedo \& Sormus 1989).

Material examinado: BRASIL. São Paulo: São Carlos, rio do Monjolinho, epilítica, bairro Babilônia, fazenda Santa Terezinha, V/1998, M.G.M. Souza s.n. (UB 01532); VI/1998 (UB 01537); VII/1998 (UB 01542); VIII/1998 (UB 01548); IX/1998 (UB 01554); X/1998 (UB 01559); São Carlos, rio do Monjolinho, epilítica, próximo à rodovia Washington Luiz, V/1998, M.G.M. Souza s.n. (UB 01533); São Carlos, rio do Monjolinho, epilítica, abaixo da Usina Hidrelétrica da CPFL, V/1998, M.G.M. Souza s.n. (UB 01534); VIII/1998 (UB 01550); São Carlos, rio do Monjolinho, epilítica, a jusante dos córregos da Água Quente e Água Fria, V/1998, M.G.M. Souza s.n. (UB 01535); VIII/1998 (UB 01551); IX/1998 (UB 01556); São Carlos, rio do Monjolinho, epilítica, $50 \mathrm{~m}$ acima da ponte da estrada, próxima à Usina da Serra, VI/1998, M.G.M. Souza s.n. (UB 01540); VIII/1998 (UB01552); IX/1998 (UB 01557); X/1998 (UB 01563); São Carlos, rio do Monjolinho, epilítica, a montante da confluência com o rio Jacaré-Guaçú, VII/1998, M.G.M. Souza s.n. (UB 01547); VIII/1998 (UB 01553); IX/1998 (UB 01558).

\section{Pinnularia borealis Ehrenebrg var. subislandica}

Krammer, Diat. Eur. 1: 25, pl. 8, fig. 1-5. 2000.

Fig. 14

Valvas lineares; extremidades truncadas; área axial linear; área central larga, definidas por estrias medianas encurtadas; rafe filiforme com extremidades proximais rafe encurvados para o mesmo lado e levemente dilatada; poros centrais distintos, arredondados; estrias largas, distantes uma das outras, levemente radiadas no centro a paralelas nas extremidades. Eixo apical: 30,0-44,6 $\mu \mathrm{m}$. Eixo transapical: 6,8-8,7 $\mu \mathrm{m}$. Estrias: $4-5 / 10 \mu \mathrm{m}$.
O material registrado para o rio do Monjolinho enquadrouse com a descrição e ilustração de Krammer (2000) para Pinnularia borealis Ehrenebrg var. subislandica Krammer, variedade nova descrita, originalmente, para a região subártica. Metzeltin \& Lange-Bertalot (2007) comentaram que este táxon foi muito freqüente para América do Sul. Além disso, e por mostrar-se semelhante ao material descrito e ilustrado por Metzeltin et al. (2005) e Metzeltin \& LangeBertalot (2007), os espécimes encontrados na área de estudo foram identificados como $P$. borealis var. subislandica.

Distribuição no Estado de São Paulo: citação pioneira para o Estado.

Material examinado: BRASIL. São Paulo: São Carlos, rio do Monjolinho, epilítica, bairro Babilônia, fazenda Santa Terezinha, V/1998, M.G.M. Souza s.n. (UB 01532); VI/1998 (UB 01537); VII/1998 (UB 01542); VIII/1998 (UB 01548); IX/1998 (UB 01554); X/1998 (UB 01559); São Carlos, rio do Monjolinho, epilítica, próximo à rodovia Washington Luiz, V/1998, M.G.M. Souza s.n. (UB 01533); São Carlos, rio do Monjolinho, epilítica, abaixo da Usina Hidrelétrica da CPFL, V/1998, M.G.M. Souza s.n. (UB 01534); VIII/1998 (UB 01550); São Carlos, rio do Monjolinho, epilítica, a jusante dos córregos da Água Quente e Água Fria, V/1998, M.G.M. Souza s.n. (UB 01535); VIII/1998 (UB 01551); IX/1998 (UB 01556); São Carlos, rio do Monjolinho, epilítica, $50 \mathrm{~m}$ acima da ponte da estrada, próxima à Usina da Serra, VI/1998, M.G.M. Souza s.n. (UB 01540); VIII/1998 (UB01552); IX/1998 (UB 01557); X/1998 (UB 01563); São Carlos, rio do Monjolinho, epilítica, a montante da confluência com o rio Jacaré-Guaçú, VII/1998, M.G.M. Souza s.n. (UB 01547); VIII/1998 (UB 01553); IX/1998 (UB 01558).

15. Pinnularia divergens W. Smith var. media Krammer, Diat. Eur. 1: 61, pl. 34, fig. 1-5. 2000.

Fig. 15

Valvas lineares; extremidades capitadas; área axial linearlanceolada, pouco expandida; área central rômbica, atingindo as margens valvares; rafe lateral, filiforme no centro; fissuras distais da rafe em forma de baioneta; estrias radiadas no centro, convergentes nas extremidades. Eixo apical: 56,9-58,1 $\mu \mathrm{m}$. Eixo transapical: $10 \mu \mathrm{m}$. Estrias: $11 / 10 \mu \mathrm{m}$.

Distribuição no Estado de São Paulo: citação pioneira para o Estado.

Material examinado: BRASIL. São Paulo: São Carlos, rio do Monjolinho, epilítica, bairro Babilônia, fazenda Santa Terezinha, VI/1998, M.G.M. Souza s.n. (UB 01537); VIII/1998 (UB 01548); IX/1998 (UB 01554).

16. Pinnularia aff. doloma Hohn \& Hellermann var.fascista Krammer, Diat. Eur. 1: 38, pl. 58, fig. 13-15. 2000.

Fig. 16

Valvas linear-lanceoladas; extremidades levemente diferenciadas do resto da valva, ligeiramente rostradas; área axial estreita, lanceolada, levemente alargada em direção ao centro; área central rômbica, atingindo as margens valvares; 
rafe filiforme; fissuras proximais da rafe voltadas para o mesmo lado; estrias ligeiramente radiadas no centro, paralelas a levemente convergentes em direção às extremidades. Eixo apical: 28,8 $\mu \mathrm{m}$. Eixo transapical: 5,6 $\mu \mathrm{m}$. Estrias: $10 / 10 \mu \mathrm{m}$.

O material registrado para o rio do Monjolinho mostrou-se bastante semelhante às ilustrações e descrição de Krammer (2000) para o táxon novo, denominado de Pinnularia doloma Hohn \& Hellermann var. fascista Krammer. Porém, por ter sido encontrado apenas um único espécime para a área estudada e este ter apresentado dados métricos menores que o da bibliografia consultada optou-se por identificá-lo como, Pinnularia aff. doloma var. fascista.

Distribuição no Estado de São Paulo: citação pioneira para o Estado.

Material examinado: BRASIL. São Paulo: São Carlos, rio do Monjolinho, epilítica, próximo à rodovia Washington Luiz, VIII/1998, M.G.M. Souza s.n. (UB 01549).

17. Pinnularia latarea Krammer var. latarea, Diat. Eur. 1: 110, pl. 84, fig. 13-15. 2000.

Fig. 17

Valvas lineares, margens levemente côncavas, no centro; extremidades capitadas; área axial estreita, lanceolada; área central rômbica, atingindo as margens valvares; rafe ligeiramente lateral; poros centrais pequenos, em forma de gota, levemente encurvados para o mesmo lado; estrias radiadas no centro, convergentes nas extremidades. Eixo apical: 50,5 $\mu \mathrm{m}$. Eixo transapical: 7,8 $\mu \mathrm{m}$. Estrias: $9 / 10 \mu \mathrm{m}$.

O material registrado para o rio do Monjolinho concordou com a descrição de Krammer (2000) e as ilustrações de Metzeltin et al. (2005), apesar de ter sido encontrado apenas um único espécime.

Distribuição no Estado de São Paulo: citação pioneira para o Estado.

Material examinado: BRASIL. São Paulo: São Carlos, rio do Monjolinho, epilítica, bairro Babilônia, fazenda Santa Terezinha, V/1998, M.G.M. Souza s.n. (UB 01532).

18. Pinnularia macilenta (Ehrenberg) Ehrenberg var. macilenta, Abh. Königl. Akad. Wiss. Berl. 1841(1): 421, pl: 2/2, fig. 4. 1841(1843).

Fig. 23

Valvas lineares, margens paralelas, ligeiramente intumescidas na região mediana; extremidades largoarredondadas; área axial larga, linear; área central rômbica, levemente assimétrica, atingindo as margens valvares; rafe lateral, filiforme no centro; fissuras proximais da rafe lateralmente encurvadas; estrias radiadas no centro, convergentes nas extremidades. Eixo apical: 96,5 $\mu \mathrm{m}$. Eixo transapical: $13,3 \mu \mathrm{m}$. Estrias: $8 / 10 \mu \mathrm{m}$.

Segundo Krammer (2000), Pinnularia macilenta (Ehrenberg) Ehrenberg 1843 foi confundida com outro táxon por Cleve em 1891 e em 1895, que considerou esta espécie muito semelhante a $P$. neomajor, que possuía margens paralelas, eixo apical de 110-150 $\mu$ m e eixo transapical de
17-20 $\mu \mathrm{m}$, com suas estrias cruzadas por uma banda longitudinal larga. No século XX todos os autores seguiram Cleve, perpetuando esta confusão, afirmou Krammer (2000). Reichardt em 1995, ao investigar o material tipo de Ehrenberg para Cayenne e Guyana Gallica, afirmou que P. macilenta era um táxon muito idêntico aos maiores morfótipos de P. subgibba do que de P. neomajor (Krammer 2000). O lectótipo de $P$. macilenta (Ehrenberg) Ehrenberg 1843, foi designado por Krammer (2000), como sendo a lâmina R1 BMB feita a partir do material tipo de Ehrenberg, por Reichardt em 1995.

Foram tratados como homônimos de $P$. macilenta Ehrenberg 1843, os seguintes táxons: Navícula macilenta Ehrenberg 1837 e 1838, P. macilenta sensu Cleve 1891 e 1895, sensu Hustedt 1930 e sensu Krammer 1992 (Krammer 2000).

A figura 5 da prancha 63 de Krammer (2000) é uma ilustração do lectótipo de P. macilenta (Ehrenberg) Ehrenberg 1843. O único espécime registrado para o Monjolinho mostrou-se muito semelhante a esta ilustração, a descrição de Krammer (2000) e as ilustrações de Reichardt (1995) para o táxon; por isso, foi identificado como P. macilenta (Ehrenberg) Ehrenberg 1843.

Distribuição no Estado de São Paulo: citação pioneira para o Estado.

Material examinado: BRASIL. São Paulo: São Carlos, rio do Monjolinho, epilítica, bairro Babilônia, fazenda Santa Terezinha, VII/1998, M.G.M. Souza s.n. (UB 01542).

19. Pinnularia meridiana Metzeltin \& Krammer var. meridiana, Icon. Diatomol. 5: 180, fig. 181: 1, 2, 4, 5.1998. Fig. 20

Valvas lineares; extremidades amplas produzidas, arredondadas; área axial larga, lanceolada; área central amplamente rômbica, atingindo as margens valvares; rafe lateral; fissuras proximais da rafe encurvadas para um dos lados; estrias radiadas no centro, convergentes nas extremidades. Eixo apical: 42,2-55,6 $\mu \mathrm{m}$. Eixo transapical: 11,2-12,7 $\mu \mathrm{m}$. Estrias: 11-12/10 $\mu \mathrm{m}$.

Distribuição no Estado de São Paulo: citação pioneira para o Estado.

Material examinado: BRASIL. São Paulo: São Carlos, rio do Monjolinho, epilítica, próximo à rodovia Washington Luiz, IX/1998, M.G.M. Souza s.n. (UB 01555).

20. Pinnularia microstauron (Ehrenberg) Cleve var. brasiliensis Krammer \& Metzeltin, Icon. Diatomol. 5: 181, figs. 179: 9-15. 1998.

Fig. 19

Valvas lineares, margens ligeiramente côncava na região mediana; extremidades rostradas; área axial estreita; área central rômbica, atingindo as margens valvares; rafe filiforme a estreitamente lateral; fissuras proximais da rafe voltadas para o mesmo lado; estrias radiadas no centro, convergentes nas extremidades. Eixo apical: 26,5-34,7 $\mu \mathrm{m}$. Eixo transapical: 6,9-8,7 $\mu \mathrm{m}$. Estrias: $10 / 10 \mu \mathrm{m}$. 
A população registrada para o rio do Monjolinho apresentou alguns espécimes com variação métrica ligeiramente inferior à descrita para o táxon; no entanto, as demais características valvares foram coincidentes com a descrição e ilustrações de Metzeltin \& Lange-Bertalot (1998).

Distribuição no Estado de São Paulo: citação pioneira para o Estado.

Material examinado: BRASIL. São Paulo: São Carlos, rio do Monjolinho, epilítica, próximo à rodovia Washington Luiz, V/1998, M.G.M. Souza s.n. (UB 01533); VIII/1998 (UB 01549); São Carlos, rio do Monjolinho, epilítica, a jusante dos córregos da Água Quente e Água Fria, VI/1998, M.G.M. Souza s.n. (UB 01539); VII/1998 (UB 01545).

21. Pinnularia obscura Krasske var. obscura, Hedwigia 72(3): 117, pl. 3, fig. 22. 1932.

Fig. 22

Valvas linear-elípticas, margens levemente convexas; extremidades amplamente arredondadas; área axial estreita, linear; área central rômbica, larga, atingindo as margens valvares; rafe filiforme; fissuras proximais encurvadas para o mesmo lado; estrias radiadas a abruptamente convergentes em direção às extremidades. Eixo apical: 17,1-19,2 $\mu \mathrm{m}$. Eixo transapical: 4,0-4,3 $\mu \mathrm{m}$. Estrias: $13 / 10 \mu \mathrm{m}$.

Distribuição no Estado de São Paulo: citação pioneira para o Estado.

Material examinado: BRASIL. São Paulo: São Carlos, rio do Monjolinho, epilítica, bairro Babilônia, fazenda Santa Terezinha, V/1998, M.G.M. Souza s.n. (UB 01532); VI/1998 (UB 01537); VII/1998 (UB 01542); VIII/1998 (UB 01548); IX/1998 (UB 01554); X/1998 (UB 01559); São Carlos, rio do Monjolinho, epilítica, próximo à rodovia Washington Luiz, VIII/1998, M.G.M. Souza s.n. (UB 01549); São Carlos, rio do Monjolinho, epilítica, a jusante dos córregos da Água Quente e Água Fria, V/1998, M.G.M. Souza s.n. (UB 01535); VI/1998 (UB 01539); VII/1998 (UB 01545); IX/1998 (UB 01556); X/1998 (UB 01562); São Carlos, rio do Monjolinho, epilítica, $50 \mathrm{~m}$ acima da ponte da estrada, próxima à Usina da Serra, VI/1998, M.G.M. Souza s.n. (UB 01540); São Carlos, rio do Monjolinho, epilítica, a montante da confluência com o rio Jacaré-Guaçú, IX/1998, M.G.M. Souza s.n. (UB 01558).

22. Pinnularia cf. oominensis Kobayasi var. oominensis, Gen. Educ. Rev., Coll. Agr. \& Vet. Med., Nihon Univ. 7: 37, pl. 9, fig. 75-76. 1971.

Fig. 21

Valvas lanceoladas; extremidades largamente atenuadoarredondadas; área axial larga, lanceolada; área central ampla, retangular, ligeiramente assimétrica, atingindo as margens valvares; rafe filiforme; fissuras proximais encurvadas para o mesmo lado; estrias levemente radiadas a convergentes nas extremidades. Eixo apical: 26,3 $\mu \mathrm{m}$. Eixo transapical: 5,6 $\mu \mathrm{m}$. Estrias: $13 / 10 \mu \mathrm{m}$.

O material mostrou-se bastante semelhante às ilustrações de Metzeltin \& Lange-Bertalot (1998; 2007), contudo, optou-se por identificá-lo como, Pinnularia cf. oominensis Kobayasi var. oominensis, porque obras contendo a descrição e a variação métrica da espécie não foram encontradas.

Distribuição no Estado de São Paulo: citação pioneira para o Estado.

Material examinado: BRASIL. São Paulo: São Carlos, rio do Monjolinho, epilítica, bairro Babilônia, fazenda Santa Terezinha, V/1998, M.G.M. Souza s.n. (UB 01532); São Carlos, rio do Monjolinho, epilítica, $50 \mathrm{~m}$ acima da ponte da estrada, próxima à Usina da Serra, VI/1998, M.G.M. Souza s.n. (UB 01540).

\section{Pinnularia parvulissima Krammer var. parvulissima,} Diat. Eur. 1: 95, pl. 65, fig. 9,10, pl. 69, fig. 7-11. 2000. Fig. 18

Valvas lineares, margens levemente convexas; extremidades largo-rostradas; área axial 1/4 do eixo transapical da valva, alargando da extremidade até a área central; área central rômbica, com uma fascia larga; rafe lateral; fissuras proximais da rafe voltadas para o mesmo lado; fissuras distais da rafe em forma de baioneta; estrias radiadas no centro, convergentes nas extremidades. Eixo apical: 38,1-38,4 $\mu \mathrm{m}$. Eixo transapical: 10,0-10,7 $\mu \mathrm{m}$. Largura da área axial: 4,0 $\mu \mathrm{m}$. Estrias: 7-9/10 $\mu \mathrm{m}$.

O material mostrou-se semelhante às ilustrações de Metzeltin \& Lange-Bertalot (2007), em especial as figuras 7 e 8 da prancha 265, e a descrição de Krammer (2000) para Pinnularia parvulissima Krammer.

Distribuição no Estado de São Paulo: citação pioneira para o Estado.

Material examinado: BRASIL. São Paulo: São Carlos, rio do Monjolinho, epilítica, próximo à rodovia Washington Luiz, V/1998, M.G.M. Souza s.n. (UB 01533); VI/1998 (UB 01538); VII/1998 (UB 01543); IX/1998 (UB 01555); X/1998 (UB 01560); São Carlos, rio do Monjolinho, epilítica, abaixo da Usina Hidrelétrica da CPFL, V/1998, M.G.M. Souza s.n. (UB 01534); VII/1998 (UB 01544); VIII/1998 (UB 01550); São Carlos, rio do Monjolinho, epilítica, a jusante dos córregos da Água Quente e Água Fria, VI/1998, M.G.M. Souza s.n. (UB 01539); VIII/1998 (UB 01551); IX/1998 (UB 01556); São Carlos, rio do Monjolinho, epilítica, $50 \mathrm{~m}$ acima da ponte da estrada, próxima à Usina da Serra, VII/1998, M.G.M. Souza s.n. (UB 01546); IX/1998 (UB 01557); São Carlos, rio do Monjolinho, epilítica, a montante da confluência com o rio Jacaré-Guaçú,V/1998, M.G.M. Souza s.n. (UB 01536); VI/1998 (UB 01541); IX/1998 (UB 01558); X/1998 (UB 01564).

\section{Pinnularia schoenfelderi Krammer var. schoenfelderi,}

Bibl. Diatomol. 26: 70, fig. 15: 1-13. 1992.

Fig. 24

Valvas linear-lanceoladas; extremidades obtusoarredondadas; área axial estreita, tornando-se lanceolada em direção ao centro; área central ampla, retangular, atingindo as margens valvares; rafe filiforme; fissuras proximais encurvadas para o mesmo lado; estrias radiadas a 

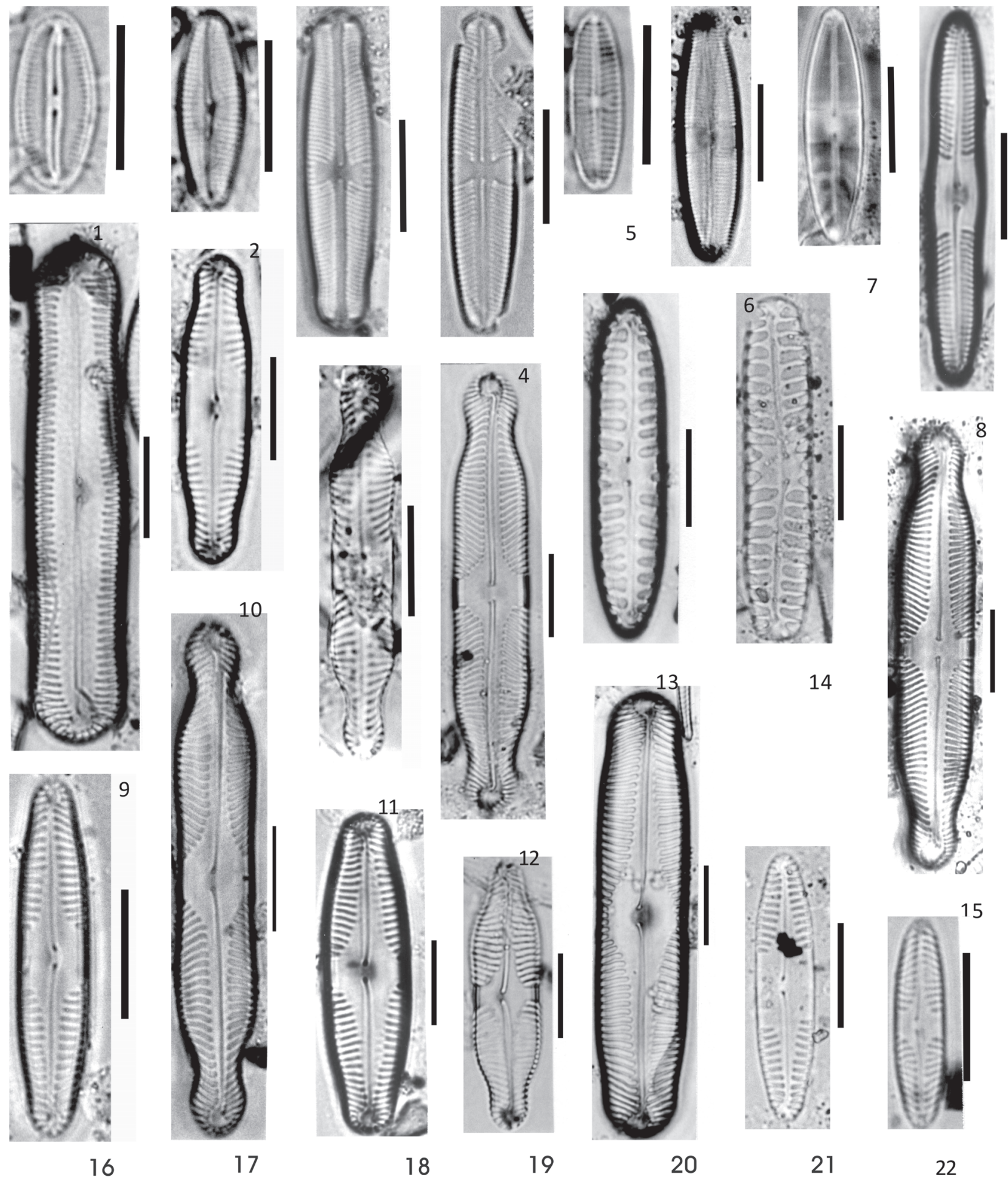

16

17

18

20

21

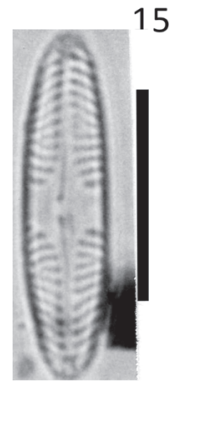

Figura 1. Fallacia insociabilis (Krasske) D.G. Mann. 2. F. monoculata (Krasske) D.G. Mann. 3. Sellaphora densistriata (Lange-Bertalot \& Metzeltin). 4. S. pseudopupula (Krasske) Lange-Bertalot. 5. S. seminulum (Grunow) D.G. Mann. 6. Caloneis bacillum (Grunow) Cleve. 7. C. hyalina Hustedt. 8. C. leptosoma (Grunow) Krammer. 9. Pinnularia acrosphaeria W. Smith. 10. P. aff. anglica Krammer. 11. P. angusta (Cleve) Krammer. 12. P. biceps Gregory. 13. P. borealis Ehrenberg var. borealis. 14. P. borealis Ehrenberg var. subislandica Krammer. 15. P. divergens W. Smith var. media Krammer. 16. P. aff. doloma Hohn \& Hellermann var. fasciata Krammer. 17. P. latarea Krammer. 18. P. parvulissima Krammer. 19. P. microstauron (Ehrenberg) Cleve var. brasiliensis Krammer. 20. P. meridiana Metzeltin \& Krammer. 21. Pinnularia cf. Oominensis Kobayasi. 22. P. obscura Krasske. Barras: $10 \mu \mathrm{m}$. 
convergentes nas extremidades. Eixo apical: $31,3 \mu \mathrm{m}$. Eixo transapical: $6,9 \mu \mathrm{m}$. Estrias: $14 / 10 \mu \mathrm{m}$.

Distribuição no Estado de São Paulo: citação pioneira para o Estado.

Material examinado: BRASIL. São Paulo: São Carlos, rio do Monjolinho, epilítica, bairro Babilônia, fazenda Santa Terezinha, V/1998, M.G.M. Souza s.n. (UB 01532); São Carlos, rio do Monjolinho, epilítica, $50 \mathrm{~m}$ acima da ponte da estrada, próxima à Usina da Serra, VI/1998, M.G.M. Souza s.n. (UB 01540).

25. Pinnularia similis Hustedt var. similis, in A. Schmidt et al., Atlas der Diatomaceenkunde, pl. 285, fig. 10-12. 1934.

Fig. 25

Valvas linear-lanceoladas, margens levemente trionduladas; extremidades capitadas; área axial estreita, linear; área central rômbica, atingindo as margens valvares; rafe complexa; estrias radiadas no centro, convergentes nas extremidades. Eixo apical: 48,7-52,7 $\mu \mathrm{m}$. Eixo transapical: 7,1-8,1 $\mu \mathrm{m}$. Estrias: $10-12 / 10 \mu \mathrm{m}$.

A população registrada para o rio do Monjolinho apresentou alguns espécimes com variação métrica ligeiramente abaixo que o da bibliografia consultada; no entanto, as demais características morfológicas foram coincidentes com o material de Krammer (2000) e Metzeltin etal. (2005).

Distribuição no Estado de São Paulo: citação pioneira para o Estado.

Material examinado: BRASIL. São Paulo: São Carlos, rio do Monjolinho, epilítica, bairro Babilônia, fazenda Santa Terezinha, V/1998, M.G.M. Souza s.n. (UB 01532); São Carlos, rio do Monjolinho, epilítica, $50 \mathrm{~m}$ acima da ponte da estrada, próxima à Usina da Serra, VIII/1998, M.G.M. Souza s.n. (UB 01552); São Carlos, rio do Monjolinho, epilítica, a montante da confluência com o rio Jacaré-Guaçú, VI/1998, M.G.M. Souza s.n. (UB 01541); VIII/1998 (UB 01553).

26. Pinnularia subanglica Krammer var. subanglica, Diat.

Eur. 1: 108, pl. 78, fig. 7, pl. 84, fig. 1-7. 2000.

Fig. 26

Valvas lineares, margens retas; extremidades capitadas; área axial estreita, linear; área central larga, rômbica, atingindo as margens valvares; rafe filiforme; poros centrais pequenos, em forma de gota; estrias radiadas no centro, convergentes nas extremidades. Eixo apical: 34,7-38,4 $\mu \mathrm{m}$. Eixo transapical: 6,5 $\mu \mathrm{m}$; Estrias: $12 / 10 \mu \mathrm{m}$.

Este táxon é muito próximo de $P$. interruptiformis Krammer, porém difere dele pelo tamanho e padrão de estriação mais grosseiro (Krammer 2000), sendo identificado como P. subanglica Krammer por concordar com Krammer (2000) e Metzeltin \& García-Rodriguez (2003) .

Distribuição no Estado de São Paulo: citação pioneira para o Estado.

Material examinado: BRASIL. São Paulo: São Carlos, rio do Monjolinho, epilítica, bairro Babilônia, fazenda Santa
Terezinha, V/1998, M.G.M. Souza s.n. (UB 01532); VI/1998 (UB 01537); VII/1998 (UB 01542); VIII/1998 (UB 01548); IX/1998 (UB 01554); X/1998 (UB 01559); São Carlos, rio do Monjolinho, epilítica, próximo à rodovia Washington Luiz, V/1998, M.G.M. Souza s.n. (UB 01533); VI/1998 (UB 01538 ); VII/1998 (UB 01543); VIII/1998 (UB 01549); IX/1998 (UB 01555); X/1998 (UB 01560); São Carlos, rio do Monjolinho, epilítica, abaixo da Usina Hidrelétrica da CPFL, V/1998, M.G.M. Souza s.n. (UB 01534); VII/1998 (UB 01544); VIII/1998 (UB 01550); X/1998 (UB 01564); São Carlos, rio do Monjolinho, epilítica, a jusante dos córregos da Água Quente e Água Fria, V/1998, M.G.M. Souza s.n. (UB 01535); VI/1998 (UB 01539); VII/1998 (UB 01545); VIII/1998 (UB 01551); IX/1998 (UB 01556); X/1998 (UB 01562); São Carlos, rio do Monjolinho, epilítica, $50 \mathrm{~m}$ acima da ponte da estrada, próxima à Usina da Serra, VI/1998, M.G.M. Souza s.n. (UB 01540); VII/1998 (UB 01546); VIII/1998 (UB01552); IX/1998 (UB 01557); X/1998 (UB 01563); São Carlos, rio do Monjolinho, epilítica, a montante da confluência com o rio Jacaré-Guaçú, V/1998, M.G.M. Souza s.n. (UB 01536); VI/1998 (UB 01541); VII/1998 (UB 01547); VIII/1998 (UB 01553); IX/1998 (UB 01558); X/1998 (UB 01564).

27. Pinnularia subcapitata Gregory var. elongata Krammer, Bibl. Diatomol. 26: 108, fig. 38: 1-11; fig. 39: 1-15. 1992.

Fig. 27

Valvas lineares a linear-elípticas; extremidades capitadas; área axial estreita, linear alargando-se próximo ao centro; área central rômbica, atingindo as margens valvares; rafe lateral, filiforme no centro; poros centrais distintos, muito próximos; estrias radiadas no centro, convergentes nas extremidades. Eixo apical: 39,7-45,4 $\mu \mathrm{m}$. Eixo transapical: 5,9-6,6 $\mu \mathrm{m}$. Estrias: 8-10/10 $\mu \mathrm{m}$.

A variedade elongata Krammer diferencia-se da variedade típica por apresentar sempre rafe distintamente lateral e filiforme na região mediana da valva.

Distribuição no Estado de São Paulo: citação pioneira para o Estado.

Material examinado: BRASIL. São Paulo: São Carlos, rio do Monjolinho, epilítica, bairro Babilônia, fazenda Santa Terezinha, VII/1998, M.G.M. Souza s.n. (UB 01542); São Carlos, rio do Monjolinho, epilítica, próximo à rodovia Washington Luiz, V/1998, M.G.M. Souza s.n. (UB 01533); IX/1998 (UB 01555); X/1998 (UB 01560); São Carlos, rio do Monjolinho, epilítica, a jusante dos córregos da Água Quente e Água Fria, VIII/1998, M.G.M. Souza s.n. (UB 01551); IX/1998 (UB 01556); X/1998 (UB 01562); São Carlos, rio do Monjolinho, epilítica, a montante da confluência com o rio Jacaré-Guaçú, V/1998, M.G.M. Souza s.n. (UB 01536).

28. Pinnularia subcapitata Gregory var. semicruciata Metzeltin \& Lange-Bertalot, Icon. Diatomol. 5: 190, fig. 173:5-13. 1998.

Fig. 28

Valvas lineares; extremidades capitadas; área axial estreita, linear; área central assimétrica, rômbica, atingindo apenas 
um dos lados da margem valvar; rafe lateral, filiforme no centro; poros centrais distintos, muito próximos; estrias radiadas no centro, convergentes nas extremidades. Eixo apical: 31,5-34,4 $\mu \mathrm{m}$. Eixo transapical: 5,4-5,6 $\mu \mathrm{m}$. Estrias: $13 / 10 \mu \mathrm{m}$.

A var. semicruciata Metzeltin \& Lange-Bertalot difere da variedade típica da espécie por apresentar uma área central que atinge a margem valvar em apenas um dos lados e por possuir maior número de estrias em $10 \mu \mathrm{m}$.

Distribuição no Estado de São Paulo: citação pioneira para o Estado.

Material examinado: BRASIL. São Paulo: São Carlos, rio do Monjolinho, epilítica, próximo à rodovia Washington Luiz, V/1998, M.G.M. Souza s.n. (UB 01533); VII/1998 (UB 01543); São Carlos, rio do Monjolinho, epilítica, $50 \mathrm{~m}$ acima da ponte da estrada, próxima à Usina da Serra, VI/1998, M.G.M. Souza s.n. (UB 01540).

29. Pinnularia subgibba Krammer var. subgibba, Bibl.

Diatomol. 26: 126, fig. 46: 1-3, 6, 7; fig. 47: 2-4, 6. 1992.

Fig. 29
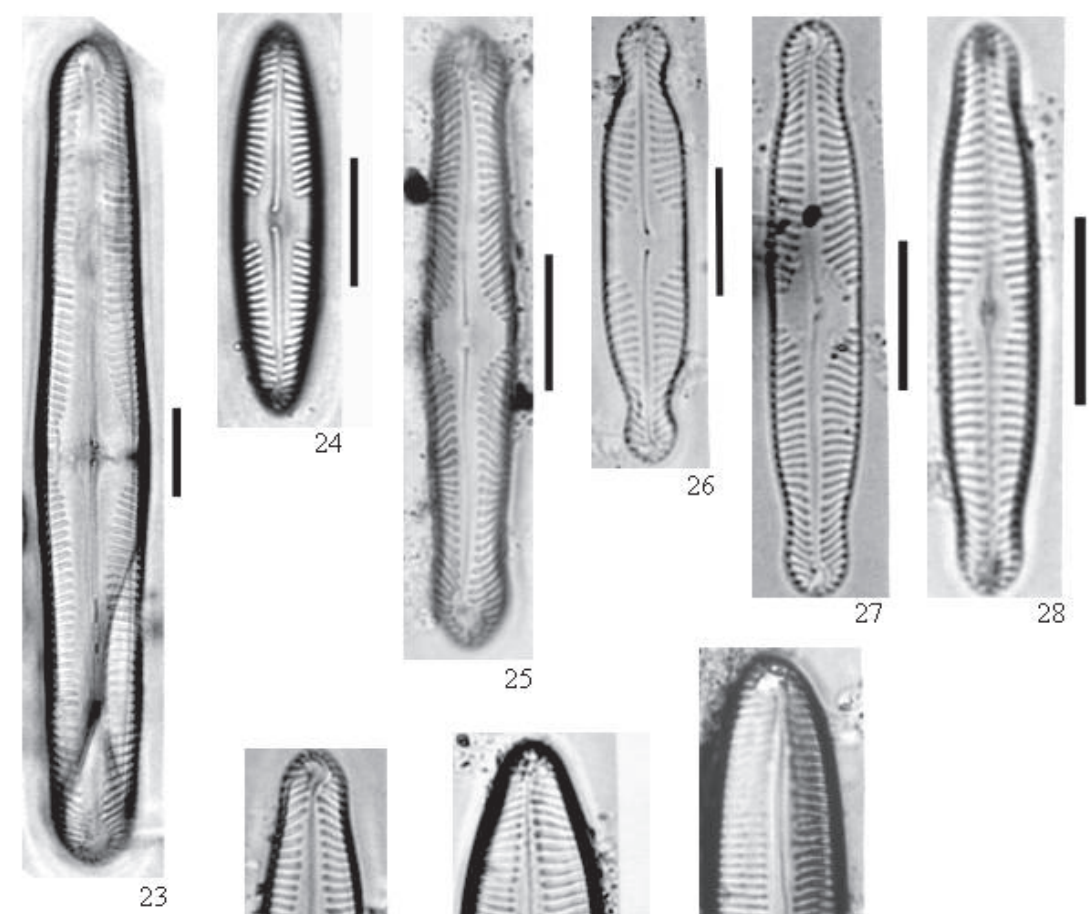
rômbica, assimétrica, atingindo as margens valvares; rafe lateral; fissuras proximais da rafe encurvadas para um dos lados; estrias radiadas no centro, convergentes nas extremidades. Eixo apical: 44,6-71,9 $\mu \mathrm{m}$. Eixo transapical: 8,4-13,3 $\mu \mathrm{m}$. Estrias: 4-10/10 $\mu \mathrm{m}$.

Distribuição no Estado de São Paulo: citação pioneira para o Estado.

Material examinado: BRASIL. São Paulo: São Carlos, rio do Monjolinho, epilítica, bairro Babilônia, fazenda Santa Terezinha, V/1998, M.G.M. Souza s.n. (UB 01532); VI/1998 (UB 01537); VII/1998 (UB 01542); VIII/1998 (UB 01548); IX/1998 (UB 01554); X/1998 (UB 01559); São Carlos, rio do Monjolinho, epilítica, próximo à rodovia Washington Luiz, V/1998, M.G.M. Souza s.n. (UB 01533); VI/1998 (UB 0 1538); VII/1998 (UB 01543); VIII/1998 (UB 01549); IX/1998 (UB 01555); X/1998 (UB 01560); São Carlos, rio do Monjolinho, epilítica, abaixo da Usina Hidrelétrica da CPFL, V/1998, M.G.M. Souza s.n. (UB 01534); VII/1998 (UB 01544);

25
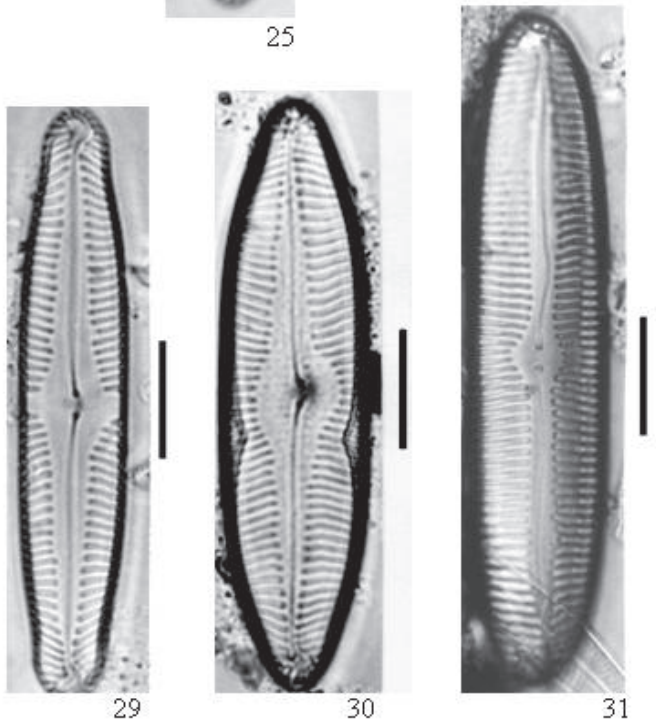

Figura 23. Pinnularia macilenta (Ehrenberg) Ehrenberg. 24. P. schoenfelderi Krammer. 25. P. similis Hustedt. 26. P. subanglica Krammer. 27. P. subcapitata Gregory var. elongata Krammer. 28. P. subcapitata Krammer var. semicruciata Metzeltin \& Lange-Bertalot. 29. P. subgibba Krammer. 30. P. variarea Metzeltin \& Krammer. 31. P. viridiformis Krammer var. minor Krammer. Barras: $10 \mu \mathrm{m}$. 
VIII/1998 (UB 01550); X/1998 (UB 01564); São Carlos, rio do Monjolinho, epilítica, a jusante dos córregos da Água Quente e Água Fria, V/1998, M.G.M. Souza s.n. (UB 01535); VI/1998 (UB 01539); IX/1998 (UB 01556); X/1998 (UB 01562); São Carlos, rio do Monjolinho, epilítica, $50 \mathrm{~m}$ acima da ponte da estrada, próxima à Usina da Serra, VI/1998, M.G.M. Souza s.n. (UB 01540); VII/1998 (UB 01546); VIII/1998 (UB01552); IX/1998 (UB 01557); São Carlos, rio do Monjolinho, epilítica, a montante da confluência com o rio Jacaré-Guaçú,V/1998, M.G.M. Souza s.n. (UB 01536); VI/1998 (UB 01541); VII/1998 (UB 01547); VIII/1998(UB 01553); IX/1998(UB 01558); X/1998 (UB 01564).

30. Pinnularia variarea Metzeltin \& Krammer var. variarea, Icon. Diatomol. 5: 194, fig. 181: 8-10; fig. 193: 5. 1998.

Fig. 30

Valvas linear-lanceoladas, margens retas; extremidades cuneadas; área axial lanceolada, expandida na região mediana; área central ampla, assimétrica, rômbica; rafe lateral; poros centrais distintos, em forma de gota, voltados para o mesmo lado; estrias radiadas no centro, convergentes nas extremidades. Eixo apical: 50,4 $\mu \mathrm{m}$. Eixo transapical: 12,5 $\mu \mathrm{m}$. Estrias: $12 / 10 \mu \mathrm{m}$.

O único espécime encontrado mostrou-se ligeiramente mais estreito que o descrito na bibliografia consultada, mas as demais características valvares foram semelhantes com a descrição de Metzeltin \& Lange-Bertalot (1998).

Distribuição no Estado de São Paulo: citação pioneira para o Estado.

Material examinado: BRASIL. São Paulo: São Carlos, rio do Monjolinho, epilítica, próximo à rodovia Washington Luiz, V/1998, M.G.M. Souza s.n. (UB 01533).

31. Pinnularia viridiformis Krammer var. minor Krammer,

Diat. Eur. 1: 167, pl. 138, fig. 1-5. 2000.

Fig. 31

Valvas lineares; extremidades cuneado-arredondadas; área axial estreita, linear; área central assimétrica, arredondada; rafe semicomplexa; poros centrais pequenos, arredondados, próximos; estrias radiadas no centro, convergentes nas extremidades; banda longitudinal moderadamente larga. Eixo apical: 65,1-68,8 $\mu \mathrm{m}$. Eixo transapical: 11,8-13,3 $\mu \mathrm{m}$. Estrias: 10/10 $\mu \mathrm{m}$.

A variedade minor Krammer difere da variedade típica da espécie por possuir variações métricas menores (Krammer 2000; Metzeltin et al. 2005).

Distribuição no Estado de São Paulo: citação pioneira para o Estado.

Material examinado: BRASIL. São Paulo: São Carlos, rio do Monjolinho, epilítica, bairro Babilônia, fazenda Santa Terezinha, VI/1998, M.G.M. Souza s.n. (UB 01537); X/1998 (UB 01559).

\section{Agradecimentos}

À Coordenação de Aperfeiçoamento de Pessoal Nível Superior (CAPES), pela Bolsa de Doutorado concedida; aos Prof. Dr. Pedro Américo Cabral Senna (in memoria) e Orlando Necchi Júnior, pela orientação; ao Programa de Pós-Graduação em Ecologia e Recursos Naturais (PPG-ERN), da Universidade Federal de São Carlos e ao Departamento de Botânica, da Universidade de Brasília, pelo apoio oferecido.

\section{Referências bibliográficas}

Bicudo, C.E.M. \& Bicudo, R.M.T. 1967. Floating communities of algae in an artificial pond in the Parque do Estado de São Paulo, São Paulo, Brazil. Journal of Phycology 3: 233-234.

Bicudo, D.C.; Bicudo, C.E.M.; Castro, A.A.J. \& Picelli-Vicentim, M.M. 1993. Diatomáceas (Bacillariophyceae) do trecho a represar do rio Paranapanema (Usina Hidrelétrica de Rosana), estado de São Paulo. Hoehnea 20: 47-68.

Krammer, K. 1992. Pinnularia eine Monographie der europäischen Taxa. Bibliotheca Diatomologica 36: 1-353.

Krammer, K. 2000. The genus Pinnularia. Diatoms of Europe 1: 1-703.

Lange-Bertalot, H. \& Metzeltin, D. 1996. Oligotrophie-Indikatoren. 800 Taxa repräsentativ für drei diverse Seen-Typen, Kalkreich Oligodystroph, Schwach gepufferttes Weichwasser. Iconographia Diatomologica 2: 1-390.

Lobo, E.A.; Callegaro, V.L.M.; Schuler, S.; Oliveira, M.A.; Salomoni, S. \& Asai. K. 1996. Pollution tolerant diatoms from rivers in the Jacuí Bacin, Rio Grande do Sul, Brazil. Iheringia Série Botânica 47: 45-72.

Magrin, A.G.E. \& Senna, P.A.C. 1997. Composição e dinâmica de diatomáceas planctônicas em uma lagoa da planície de inundação do médio Mogi-Guaçu, estado de São Paulo, Brasil. Anais do VII Seminário Regional de Ecologia 8: 247-276.

Metzeltin, D. \& Lange-Bertalot, H. 1998. Tropical Diatoms of South America I. Iconographia Diatomologica 5: 1-695.

Metzeltin, D. \& García-Rodrígues, F. 2003. Las diatomeas Uruguayas. Montevideo, D.I.R.A.C. - Universidad de la República, Facultad de Ciências.

Metzeltin, D.; Lange-Bertalot, H. \& García-Rodríguez, F. 2005. Diatoms of Uruguay. Ruggell, A.R.G. Gantner Verlag.

Metzeltin, D. \& Lange-Bertalot, H. 2007. Tropical Diatoms of South America II. Iconographia Diatomologica 18: 1-877.

Moreira Filho, H. \& Valente-Moreira, I.M. 1981. Avaliação taxonômica e ecológica das diatomáceas (Bacillariophyceae) epífitas em algas pluricelulares obtidas nos litorais dos estados do Paraná, Santa Catarina e São Paulo. Boletim Museu Botânico Municipal 47: 1-17.

Reichardt, E. 1995. Die Diatomeen in Ehrenbergs Material von Cayenne, Guyana Gallica (1843). Iconographia Diatomologica 1: 1-107.

Round, F.E.; Crawford, R.M. \& Mann, D.G. 1990. The diatoms: biology and morphology of the genera. Cambridge, Cambridge University Press.

Sant'Anna, C.L.; Azevedo, M.T.P. \& Sormus, L. 1989. Fitoplâncton do lago das Garças, Parque Estadual das Fontes do Ipiranga, São Paulo, Brasil: estudo taxonômico e aspectos ecológicos. Hoehnea 16: 89-131.

Simonsen, R. 1974. The diatom plankton of the Indian Ocean Expedition of R/V "Meteor", 1964-1965. "Meteor" Forsch.Ergebnisse Reihe D-Biological 19: 1-66.

Tundisi, J.G. \& Hino, K. 1981. list of species and growth seasons of phytoplankton from Lobo (Broa) Reservoir. Revista Brasileira de Biologia 41: 63-68.

Xavier, M.B.; Monteiro-Junior, A.J. \& Fujiara, L.P. 1985. Limnologia de reservatórios do sudoeste do estado de São Paulo, Brasil, 6: fitoplâncton. Boletim do Instituto de Pesca 12: 145-186.

Versão eletrônica do artigo em www.scielo.br/abb e http://www.botanica.org.br/acta/ojs 